\title{
Blood pressure distribution in responders and initial non-responders in a population screening study
}

\author{
ALAN J SILMAN AND CELINA M LOCKE \\ From the Department of Clinical Epidemiology, London Hospital Medical College, London E1 2AD, UK
}

SUMMARY The distribution of diastolic blood pressure (DBP) was compared between those who responded to a first written request to attend at their general practitioner's surgery for screening for hypertension and those who needed more intensive effort encouraging them to attend. After excluding $25 \%$ of the population whose current address could not be traced, $92 \%$ of the remainder were eventually seen and screened. There was no association between diastolic blood pressure and effort needed to bring the patient to screening, and this applied to all patients both with and without a history of hypertension. Thus it appears that unlike screening for cervical cancer, screening for hypertension may not selectively tend to miss the groups most at risk.

There is general agreement that screening for hypertension should attempt to cover the whole population and that in the United Kingdom, general practice provides the most appropriate baseline population. ${ }^{1}$ There are an increasing number of reports of screening for hypertension in general practice where the practice population have been invited to attend for screening. ${ }^{2-7}$ The non-response rate was generally around $20-25 \%,{ }^{35}$ though in ideal circumstances with enthusiastic general practitioners and a compliant patient population the non-response rate may be as low as $10 \% .{ }^{8}$ It is important, however, in evaluating the effectiveness of screening for hypertension to assess the prevalence of hypertension in non-responders. Hodes $\mathrm{et} \mathrm{al}^{4}$ found that of the non-responders who later attended their general practitioner for some other reason, the prevalence of hypertension was higher than that in the screening response group. Fulton et al observed no difference in history of hypertension between screening responders and non-responders (paper presented at IX International Scientific Meeting, International Epidemiological Association, Edinburgh, 1981).

This study based on the East London Hypertension Programme ${ }^{8}$ investigates whether there is an association between response to screening and distribution of blood pressure. In two of the participant practices intensive efforts were undertaken to screen the entire population. Such an analysis also provides data on the yield from screening with increasing effort at detection and is of value for determining the most cost-effective screening strategy.

\section{Subjects and methods}

Subjects were all patients aged 50 to 65 on 1 January 1980 in two general practices, one a single-handed practice and the other a health centre based group in the London Borough of Hackney. The patients were identified simultaneously during the compilation of age/sex registers by the local family practitioner committee. Patients for whom subsequent exhaustive inquiries in the practices, local post office, and from neighbours failed to provide a correct current address were excluded from the analysis. Also excluded were nine patients who were in hospital and four who were physically unable to attend a screening clinic. Thus 1042 patients were potentially available to attend.

Each patient was sent an invitation signed by their own general practitioner asking him/her to attend on one of three dates and times for screening. Patients who requested an alternative time were sent a further appointment and counted as a first attender. All nonattenders had their addresses checked and if appropriate a second "first" invitation was sent to the new address. A failure to attend after the first invitation was followed by a second and, if necessary, a third request. The patient was visited at home if no response had been received after three letters.

All blood pressures were recorded by the same observer (CML), using the Hawksley random zero sphygmomanometer. All blood pressure readings were taken in the right arm, seated. If the initial diastolic blood pressure was greater than $89 \mathrm{~mm} \mathrm{Hg}$ then a second reading was taken after five minutes and the mean of the two recordings calculated. All diastolic blood pressures were recorded at the fifth 
sound. The distribution of the population by diastolic blood pressure was achieved by allocation to one of three groups: (1) Normotensive: DBP $\leqslant 94 \mathrm{~mm} \mathrm{Hg}$; (2) Borderline: DBP 95-104 mm Hg; (3) Hypertensive: DBP $\geqslant 105 \mathrm{~mm} \mathrm{Hg}$. Differences in the distribution of diastolic blood pressure between the screening groups were assessed using the $\chi^{2}$ test.

\section{Results}

Overall, $85(8 \cdot 2 \%)$ of the patients did not have their blood pressure recorded: of these, only six $(0.6 \%)$ were outright refusals; the remainder could not be contacted either by post or at home.

Table 1 shows the numbers attending and the response rate at each stage of the screening. Nearly two-thirds of those eligible to attend attended at the first request and about half of the remainder at the second. Though, as expected, the response rate fell as initial non-responders were further screened, surprisingly, $40 \%$ of those who received three letters attended at that stage. The $35 \%$ "responding" to home visits reflects the proportion at present home

Table 1 Patients attending at each stage of screening programme

\begin{tabular}{lcrrl}
\hline Stage & $\begin{array}{l}\text { Requests } \\
\text { sent* }\end{array}$ & $\begin{array}{l}\text { No } \\
\text { seen }\end{array}$ & (\%) & $\begin{array}{l}\text { Response } \\
\text { rate }\end{array}$ \\
\hline 1st request & 1042 & 654 & $(62 \cdot 8)$ & $62 \cdot 8 \%$ \\
2nd request & 388 & 164 & $(15 \cdot 7)$ & $42 \cdot 2 \%$ \\
3rd request & 224 & 94 & $(9 \cdot 0)$ & $41 \cdot 9 \%$ \\
Home visit & 130 & 45 & $(4 \cdot 3)$ & $34.6 \%$ \\
Not seen & & 85 & $(8 \cdot 2)$ & \\
Total & & 1042 & $(100)$ & \\
\hline
\end{tabular}

-Number visited in the case of home visits.

Table 2 Diastolic blood pressure by visit of attendance

\begin{tabular}{|c|c|c|c|c|c|c|c|}
\hline \multirow[b]{2}{*}{ Visit } & \multicolumn{6}{|c|}{ Diastolic BP ( $\mathbf{m m ~ H g})$} & \multirow[b]{2}{*}{$\begin{array}{l}\text { Total } \\
\text { No }\end{array}$} \\
\hline & $\begin{array}{l}\leq 94 \\
\text { No }\end{array}$ & \% & \multicolumn{2}{|c|}{$95-104$} & \multicolumn{2}{|c|}{$\geqslant 105$} & \\
\hline \multicolumn{8}{|c|}{ Patients with no history of hypertension } \\
\hline 1st & 484 & $83 \cdot 3$ & 68 & 11.7 & 29 & $5 \cdot 0$ & 581 \\
\hline 2nd & 121 & 85.2 & 16 & 11.3 & 5 & 3.5 & 142 \\
\hline 3rd & 72 & 84.7 & 10 & 11.8 & 3 & $3 \cdot 5$ & 85 \\
\hline Home & 33 & 91.7 & 3 & $8 \cdot 3$ & $\mathbf{0}$ & - & 36 \\
\hline Total & 710 & 84.1 & 97 & 11.5 & 37 & 4.4 & 844 \\
\hline \multicolumn{8}{|c|}{ Patients with previously diagnosed hypertension } \\
\hline 1st & 36 & $49 \cdot 3$ & 28 & 38.4 & 9 & $12 \cdot 3$ & 73 \\
\hline 2nd & 11 & 50.0 & 9 & 40.9 & 2 & $9 \cdot 1$ & 22 \\
\hline 3rd & 4 & 40.4 & 3 & $33 \cdot 3$ & 2 & $22 \cdot 2$ & 9 \\
\hline Home & 5 & 55.5 & 3 & $33 \cdot 1$ & 1 & $11 \cdot 1$ & 9 \\
\hline Total & 56 & 49.6 & 43 & $38 \cdot 1$ & 14 & $13 \cdot 4$ & 113 \\
\hline \multicolumn{8}{|c|}{ All patients } \\
\hline 1st & 520 & 79.5 & 96 & 14.7 & 38 & 5.8 & 654 \\
\hline 2nd & 132 & 80.5 & 25 & 15.2 & 7 & $4 \cdot 3$ & 164 \\
\hline 3rd & 76 & 80.9 & 13 & 13.8 & 5 & $5 \cdot 3$ & 94 \\
\hline Home & 38 & 80.5 & 6 & $13 \cdot 3$ & 1 & $2 \cdot 2$ & 45 \\
\hline Total & 766 & $80 \cdot 1$ & 140 & 14.5 & 51 & $5 \cdot 3$ & 957 \\
\hline
\end{tabular}

and is not a true response rate, refusals, as indicated, being few. The patients were divided up into those with previously known hypertension $113(11 \cdot 8 \%)$, and those without, as this might have affected response. There was, overall, no difference in distribution of attendance between these two groups $\left(\chi^{2}=4.0,3 \mathrm{df}, \mathrm{p}>0.05\right)$ though the proportion of those previously diagnosed "seen at home" (8.0\%) was higher than those with no history $(4 \cdot 3 \%)$.

There was no observed association between attendance and diastolic blood pressure irrespective of hypertension history (table 2). As the yield, however, for a given level of screening is a function of both hypertension rate and attendance, in the present study nearly $80 \%$ of all newly discovered "hypertensives" came as a result of the first request (table 3). Home visiting detected only one patient with diastolic blood pressure $>105 \mathrm{~mm} \mathrm{Hg}$ (who was a previously diagnosed hypertensive and had lapsed from this treatment). Similarily, of 140 "borderliners" discovered, only six (4\%) were picked up at home while $70 \%$ were picked up at the first request.

\section{Discussion}

There are three reservation in applying these results to other groups. Firstly, our population was from a deprived inner urban area and behaviour patterns may vary in other groups. Nevertheless, we have detected no differences in response by diastolic blood pressure distribution among the different socioeconomic groups in this study. Secondly, we were unable to discover a current address for a quarter of the population identified from the age/sex registers. This group being highly mobile may not be poor attenders and in addition might have a different risk for hypertension. Within the population, though, we were able to identify a subgroup for whom,

Table 3 Percentage frequency distribution of patients with a high diastolic blood pressure by visit of attendance

\begin{tabular}{|c|c|c|c|c|}
\hline \multirow[b]{2}{*}{ Visit } & \multicolumn{2}{|c|}{ Newly discovered } & \multicolumn{2}{|c|}{$A u_{\text {patients }}$} \\
\hline & No & $\%$ & No & \% \\
\hline \multicolumn{5}{|c|}{ Diastolic blood pressure $95-104 \mathrm{~mm} \mathrm{Hg}$} \\
\hline 1st & 68 & 70.1 & 96 & $68 \cdot 6$ \\
\hline 2nd & 16 & $16 \cdot 5$ & 25 & $17 \cdot 9$ \\
\hline 3rd & 10 & $10 \cdot 3$ & 13 & $9 \cdot 3$ \\
\hline Home & 3 & $3 \cdot 1$ & 6 & $4 \cdot 2$ \\
\hline Total & 97 & 100 & 140 & 100 \\
\hline \multicolumn{5}{|c|}{ Diastolic blood pressure $\geqslant 105 \mathrm{~mm} \mathrm{Hg}$} \\
\hline 1st & 29 & $78 \cdot 4$ & 38 & $74 \cdot 5$ \\
\hline 2nd & 5 & 13.5 & 7 & 13.7 \\
\hline 3rd & 3 & $8 \cdot 1$ & 5 & 9.8 \\
\hline Home & 0 & 0 & 1 & $2 \cdot 0$ \\
\hline Total & 37 & 100 & 51 & 100 \\
\hline
\end{tabular}


despite difficulty, a current address was eventually found. Small numbers do not permit any meaningful examination of response by distribution of diastolic blood pressure in this subgroup, but the figures do not show any obvious differences from the population as a whole. Thirdly, though the same observer performed all the measurements, the distribution of diastolic blood pressure for those recorded at home would probably differ from those recorded in the general practitioner's surgery. It is difficult to predict whether familarity of home circumstances would "compensate" for the unexpectedness when home visiting was used for screening. The results, however, found no association between screening response and diastolic blood pressure. It is unlikely, therefore, that, compared with screening for cervical cancer, 9 factors associated with increased risk for hypertension are not themselves associated with attendance at screening. We did not confirm the experience of Hodes et al in finding a subsequently high prevalence of hypertension in screening non-responders, but in that study only those non-responders who reattended their general practitioner were reviewed.

As increasing screening effort only increased the yield of hypertensives in a direct proportion to the response rate the actual cost to capture different proportions of the hypertensive population by screening can be calculated.

We are grateful to Dr CFranklin and Drs $T$ Worth, $S$ Hasenson, A Clein, and D Keene together with their reception staff for help and co-operation; to $\mathrm{Dr} G$ Walker, Dr F Murphy, and Professor J N Morris, who were closely concerned with the design of the East London Hypertension Study; and to Mr D Hill and Mr S Evans for help with the data processing.

This study was funded as part of the East London Hypertension Study by a grant from the City and East London Area Health Authority.

\section{References}

${ }^{1}$ Anonymous. Millions of mild hypertensives. $\mathrm{Br}$ Med J 1980; 281: 1024-5

${ }^{2}$ Adler MW, Marson WS. Randomised controlled trial of treatment of moderate hypertension in general practice: a feasibility study. Proc R Soc Med 1973; 66: 38-41.

'D'Souza MF, Swan AV, Shannon DJ. A long-term controlled trial of screening for hypertension in general practice. Lancet 1976; i: 1228-31.

4 Hodes C, Rogers DA, Everitt MG. Identification and treatment of arterial hypertension in general practice. Clin Sci Mol Med 1976; 51: 657s-9s.

sHawthorne VM. Multiphasic screening in general practice. Lancet 1978, i: 1038-9.

-Thomson DMM, Rawlins DC. Hypertension and general practice. Br Med J 1980, i: 109.

${ }^{7}$ MRC Working Party. Randomised controlled trial of treatment for mild hypertension: design and pilot trial. Br Med J 1977; i: 1437-40

- Silman AJ, Murphy FW. Hypertension and general practice. Br Med J 1980; 280: 399.

Anonymous. Management of abnormal cervical smears. Br Med J 1980; 280: 1239-40. 